\title{
Impact of Consumer Profiles on a Consumer Convenience Prioritised Demand Response
}

\author{
Chittesh Veni Chandran \\ Technological University Dublin, chitteshvc@gmail.com \\ Keith Sunderland \\ Technological University Dublin, keith.sunderland@tudublin.ie \\ Malabika Basu \\ Technological University Dublin, malabika.basu@tudublin.ie
}

Follow this and additional works at: https://arrow.tudublin.ie/engscheleart

Part of the Electrical and Computer Engineering Commons

\section{Recommended Citation}

C. V. Chandran, K. Sunderland and M. Basu, "Impact of Consumer Profiles on a Consumer Convenience Prioritised Demand Response," 2019 54th International Universities Power Engineering Conference (UPEC), 2019, pp. 1-6, doi: 10.1109/UPEC.2019.8893502.

This Conference Paper is brought to you for free and open access by the School of Electrical and Electronic Engineering at ARROW@TU Dublin. It has been accepted for inclusion in Conference papers by an authorized administrator of ARROW@TU Dublin. For more information, please contact arrow.admin@tudublin.ie, aisling.coyne@tudublin.ie,gerard.connolly@tudublin.ie.

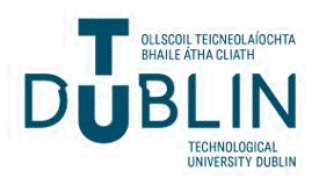




\section{Impact of Consumer Profiles on a Consumer Convenience Prioritised Demand Response}

\author{
Chittesh Veni Chandran \\ Technological University Dublin, Ireland \\ School of Electrical Engineering Systems \\ chittesh.vc@mydit.ie
}

\author{
Keith Sunderland \\ Technological University Dublin, Ireland \\ School of Electrical Engineering Systems \\ keith.sunderland@dit.ie
}

\author{
Malabika Basu \\ Technological University Dublin Ireland \\ School of Electrical Engineering Systems \\ malabika.basu@dit.ie
}

\begin{abstract}
Distribution network (DN) load flexibility has simultaneously created challenges and opportunities. The major challenge is to meet the demand-supply balance while maintaining a positive profit-loss ratio. Further, Government enforced climate change policies attract low carbon technology (LCT) distributed energy resources (DER), which further complicate matters. Along with DN, the domestic appliance industry has undergone drastic modernization leading to appliances with advanced control and power efficient technologies as well as automation capabilities. This paper proposes a demand response (DR) program that facilitates these advancements while micromanaging the domestic load consumption pattern so as to manage peak demand in the network. This work identifies consumer conviction towards the DR programs as the major bottle neck for the success of such load management programs. The mixed integer linear programming based DR (MILP - DR) algorithm proposed here, minimizes the consumer inconvenience while facilitating load reduction. Further, attractive consumer engagement plans promoting different levels of engagement (load reduction) are also proposed, which further enhance the choice offering for consumers. The algorithm is tested on a 74 load (domestic) urban distribution network having 8 different consumer profiles. The algorithm is capable of inducing impartiality between consumers by updating a tolerance factor correlating inconvenience of consumers with load deprivation. The results show the capability of the algorithm to distribute load reduction based on the engagement plan, while also minimizing the consumer inconvenience. The results also suggest correlations between social parameters and achievable DR.
\end{abstract}

Index Terms-- Demand response, demand side management, Energy management, Consumer Comfort, Consumer behaviour, Integer linear programming

\section{INTRODUCTION}

Managing the energy demand-supply balance - along with increases in demand - has created the impetus to modernise the low voltage distribution network (LVDN). This, along with decentralization of electrical systems, has led to the adaptation of private/public owned distributed energy resources, strategically placed battery systems, increased investment in building reliable infrastructure, fast communication and control technology, and competition between the suppliers. As a trillion-dollar industry, the market for even a simple load demand restructuring creates huge opportunities for financial rewards. Thus, DR programs, if successful, can create significant profit to the actors as well as the aggregators.

In literature, different demand response technologies are proposed [1], but there are two major classifications for these programs: Price based and Incentive based. Yet again, these categories can be sub classified into many more based on their application and techniques of implementations. Demand response are not only applied for peak load management but also are used as a solution to maximize solar PV utilization, optimizing battery storage, regulating emissions, solving reliability issues, utilizing flexibility of electric vehicle, and many more [2][3][4]. Further, numerous techniques are also applied of achieve DR in literature such as model predictive control [5], heuristic optimization based [6], agent based modelling [7], mixed integer programming [8] and machine learning based demand response [9] etc. However, the methodology applied to achieve the demand response is usually dependent on the objective/application and is generally chosen by the programmer based on his knowledge and intuition. Here, a mixed integer linear programming (MILP) is implemented using MOSEK solver in CVX toolbox in MATLAB environment.

In spite of the success hailed by DR algorithms in the research and literature, the implementation of such programs has never taken place on a large scale. In 2013 the European Commission pointed out that, "... [the] potential of the demand side response at the Union scale is enormous: peak demand could be reduced by $60 \mathrm{GW}$, approximately $10 \%$ of EU's peak demand". This again being a significant topical statement hasn't improved the situation beside few piolet studies and reports. One of the major influencing factors for such programs (after technology implementation) is consumer acceptance.

The study performed by authors in [10] shows that, the participation of a consumer in DR would result in inconvenience, higher for larger load, and would influence the participation of consumer. Further, authors of [11] indicates to the importance of consumer awareness and clarity to the success of a DR program and proposes a engagement plan based thermostat control. Consumer behaviour based model presented in [12], again identifies the importance of consumer satisfaction towards the success of DR program. The paper also points out that, the incentive based DR program has a higher influence on consumers (than the price based) towards consumer response. Brain Seal of the Electric Power Research 
Institute (EPRI), states, "The industry is only at the beginning of learning to understand their customers and figuring out what people want to do"[13]. The requirements of people are so diverse; dependent on social and demographic parameters leading to extreme difficulties in generalising an engagement plan/DR program. The European Commission [14], points out that, consumers should be given the right incentives to encourage more active engagement and contribution to system performance and stability. For instance, a survey conducted by Opower [15], shows the consumers feels it is important for suppliers to notify about the critical periods and the tariff associated.

This paper utilizes a consumer inconvenience factor to dictate consumer engagement plans provided for consumers and regulate the participation of a consumer in load reduction. The engagement plan can be utilized to define different levels of incentives to motivate consumer to choose high reduction plan. The MILP-DR would also consider fairness between consumers and consumer devices using inconvenience/tolerance factor safeguarding against repeated participation for long period. The performance of the algorithm is evaluated against 8 different consumer (demand) profiles distributed in 74 loads and having different engagement plans.

\section{Methodology}

The objective of DR program is to alter the energy consumption pattern from the nominal consumption pattern in response to price of electricity or peak load. The DR program presented in this work is executed in two level: aggregator level and consumer level. The aggregator level initiates the DR program when they load reduction request is received from the utility. The load reduction is then distributed by a linear programming (LP) program based on the consumer engagement plan. The second stage of the program is executed for each individual house according to the reduction calculated in the previous stage. The reduction is obtained by managing the operation of non-critical loads in the house based on their associated inconvenience values, which can be assigned by the consumer.

\section{A. Consumer engagement plans}

As consumer participation is key for a successful DR program, the engagement plan offered must be very attractive while providing enough options for all different types of consumers. Engagement plans can be device based on various factors which would influence the decision of consumer. Whereas monetary benefits are considered as prime for DR program attraction, the lower scale of such benefits has seldom initiated voluntary engagement by consumers. The literature shows that a correlation between social and environmental benefits has superior convincing capability as opposed to money being the sole motivator. Keeping these facts in mind four different consumer engagement plans are identified:

Super Green Savvy (SGS) ( $\alpha \in[0.2-0.5))$ : consumers who are very much aware and motivated by the social and environmental benefits of DR and are willing to tolerate high load reduction when needed. These consumers are highly rewarded for their availability and also gets their reward on the share of reduction.
Green Savvy (GV) $(\alpha \in[0.5-0.7))$ : Consumers who are aware of DR benefits but are not willing to tolerated as much as the first category.

Green Aware (GA) $(\alpha \in[0.7-1))$ : Consumers who are willing to test and participate but are (sceptical) not willing to sacrifice much regarding their comfort.

Reluctant $(\mathrm{R})(\alpha=1)$ : Consumers who are not willing to participate in the DR program. They are not penalised for their decision but are also not benefited from the program in any manner.

For different engagement plans, a corresponding tolerance $(\alpha \alpha)$ value is initiated and included in the plan. The MILP-DR program will be utilizing these values to regulate the demand reduction and would also update these values based on the consumer participation (ensuring fairness between consumers in same plan)

\section{B. Consumer profiles}

The proposed work evaluates the performance and impact of MILP-DR on the different classes of consumers classified based on social and demographic identifiers. With different consumer categories, the power consumption pattern (appliance usage pattern) is different and can impact the capability of DR in load reduction (while minimizing consumer inconvenience). The impact is assessed in terms of the load reduction accommodated by each class of consumers with different engagement plans as described in the previous section.

The classification utilized in this work is provided below along with the parameters used in the classification. Each of these categories represent a change in electricity consumption pattern

\begin{tabular}{|l|l|c|c|l|}
\hline \multicolumn{1}{|c|}{} & $\begin{array}{l}\text { House } \\
\text { type }\end{array}$ & $\begin{array}{l}\text { Number } \\
\text { of People }\end{array}$ & Children & Type of Day \\
\hline Profile 1 & Detached & 2 & No & Workday \\
\hline Profile 2 & $\begin{array}{l}\text { Semi } \\
\text { Detached }\end{array}$ & 3 & Yes & Workday \\
\hline Profile 3 & $\begin{array}{l}\text { Semi } \\
\text { Detached }\end{array}$ & 4 & No & Workday \\
\hline Profile 4 & $\begin{array}{l}\text { Semi } \\
\text { Detached }\end{array}$ & 4 & No & holiday \\
\hline Profile 5 & Flat & 2 & No & Workday \\
\hline Profile 6 & Flat & 2 & No & Holiday \\
\hline Profile 7 & Terrace & 4 & yes & Workday \\
\hline Profile 8 & Terrace & 4 & yes & Holiday \\
\hline
\end{tabular}

\section{MILP-DR Modelling}

The objective of the proposed DR is to minimize the consumer inconvenience while achieving the required load reduction. This section would present the modelling technique utilized to achieve the proposed DR. The objective is constrained by the operation limits which ensures feasible solution. The implementation is executed in MATLAB environment with CVX using MOSEK solver.

Assume a feeder feeding ' $n$ ' number of consumers in the network at any given time ' $t$ '. The total load can be written as, 


$$
P_{\text {Total }}(t)=\sum_{j=1}^{n} P_{j}(t)
$$

Where, $P_{j}$ is the power consumed by the jth consumer. Since this analysis is carried out at steady state, the time dependency is eliminated from here on. The total loads ('i') in the domestic environment are classified as critical and non-critical loads. The critical loads are those which are essential for the user when it is requested and can't be turned off by the DR program. The non-critical loads however, can be controlled/denied with inconvenience induced in consumer based on the particular device. Now, the Equation (1) Error! Reference source not found.can be written as,

$$
P_{\text {Total }}=\sum_{j=1}^{n}\left(\sum_{i=1}^{m}\left(P_{i j}{ }^{N C}+P_{i j}{ }^{C}\right)\right)
$$

Where, $P_{i j}{ }^{N C}$ is a vector of power consumed by the individual non-critical devices and $P_{i j}{ }^{C}$ represents the vector of power consumed by the individual critical devices, $i \in$ $\{1,2,3, \ldots \ldots m\}, j \in\{1,2,3, \ldots \ldots n\}$. However, at any given instance it is very unlikely that household would request for all the loads simultaneously. Hence, the demand of the domestic household is given by,

$$
A_{j}=\left\{\begin{array}{llllll}
D_{1} & D_{2} & D_{3} & \ldots & \ldots & D_{m}
\end{array}\right\}
$$

Where $D_{1}$ is the status of the device given by $[0,1]$. The total demand of the network is given by,

$$
A_{i j}=\left\{\begin{array}{c}
A_{1} \\
A_{2} \\
A_{3} \\
\ldots . \\
A_{n}
\end{array}\right\}
$$

The vector $A_{i j}$ gives the status of the ith device of the jth consumer. Now the total load at any given time can be given as,

$$
P_{\text {Total }}=\sum_{j=1}^{n}\left(\sum_{i=1}^{m} A_{i j}\left(P_{i j}{ }^{N C}+P_{i j}{ }^{C}\right)\right)
$$

The demand status vector $\left(A_{i j}\right)$ is time dependent which changes depending on consumer demand. The DR is initiated when a reduction request is received from the grid operator. The first stage of DR program would distribute the demand reduction to consumers based on the consumer engagement plan selected by each consumer. The objective function is focused in minimizing the total inconvenience, ' $\alpha_{j}$ ', faced by the consumers while achieving DR. Hence objective becomes,

$$
\operatorname{minimize}\left(\sum_{j=1}^{n}\left(\propto_{j} \Delta P_{j}\right)\right)
$$

The value of ' $\alpha_{j}$ ' can be anywhere in between 0 and 1 , where 1 being not willing to participate. $\Delta P_{j}$ is the individual load reduction requested by each consumer with corresponding ' $\propto_{j}$ ' described by their engagement plan. This ensures the consumer with high inconvenience would participate less in load reduction and the consumers with low inconvenience would be major actors in load reduction. This objective is subjected to constraints defined by,

$$
\begin{gathered}
\Delta P=P_{\text {Total }}-P_{\text {Peak }} \\
\Delta P_{j} \leq 0.5 P_{j} \\
\Delta P \leq \sum_{j=1}^{n} \Delta P_{j} \\
0 \leq \propto_{i j} \leq 1
\end{gathered}
$$

The maximum reduction possible from a house is restricted to $50 \%$ to ensure that a consumer with very low inconvenience would not have to suffer total black out of non-critical load. This, however, would unfairly penalise the consumer choosing the low inconvenience plan as the algorithm would repeatedly choose them for major load reduction. This is eliminated by using a weight update factor for updating the value of inconvenience based on the contribution/participation measured by the load reduction and the amount of time load reduction is imposed. This ensures the fairness in the operation of DR program which is a key parameter for consumer satisfaction.

The second stage of the algorithm initiates the device schedule on non-critical device, again based on inconvenience factor ' $\beta_{i j}$ ' related device chosen by consumer. A weight update factor can be initiated to induce fairness between the devices chosen in each interval. This study ignores it as the counter system installed in the algorithm keeps track of the devices operation denials and would inhibit the denial after a set number of times. As well as this however, the (algorithm) counter also makes sure the requested device is operated at a later stage to fulfil the consumer demands for the day. The output of second stage produces a device operation status vector $B_{j}$ which provides the information of list of devices operating after DR engagement.

$$
B_{j}=\left\{\begin{array}{llllll}
D_{1} & D_{2} & D_{3} & \ldots & \ldots & D_{m}
\end{array}\right\}
$$

Where, the $\mathrm{D}$ is again the device status vector having value $[0,1]$. The total allowed load after DR in the network is given by,

$$
B_{i j}=\left\{\begin{array}{c}
B_{1} \\
B_{2} \\
B_{3} \\
\cdots \\
B_{n}
\end{array}\right\}
$$

The device denied operation is,

$$
R_{i j}=\left(A_{i j}-B_{i j}\right)
$$

The amount of reduction in load can be obtained by,

$$
\Delta P_{r}=\sum_{j=1}^{n}\left(\sum_{i=1}^{m} R_{i j} P_{i j}{ }^{N C}\right)
$$


Similar to the previous stage, the objective of this stage of DR, while achieving the demand reduction, is to minimize the inconvenience occurring to the consumers while the operation of certain devices are denied. Thus, the objective function is to,

$$
\operatorname{Minimize}\left(\sum_{j=1}^{n} \beta_{j} R_{j}\right)
$$

Subject to,

$$
\begin{gathered}
\Delta P_{j} \leq \sum_{i, j=1}^{n, m} R_{i j} P_{i j} \\
0 \leq \beta_{i j} \leq 1 \\
\Delta P \leq \sum_{j=1}^{m} \Delta P_{j}
\end{gathered}
$$

The sum of load reduction in each house would be equal to or less than the value dedicated by the previous stage. The total reduction achieved by the algorithm may be less than the reduction warranted by the operator, however, this is the sacrifice the aggregator might have to make to achieve greater benefits (consumer acceptance, higher participation)

\section{RESULTS AND DISCUSSIONS}

The MILP-DR is implemented on a representative 74 load (Houses) low voltage urban distribution network (Dublin, Ireland). The residential load data and consumer profile data are obtained from the household electricity survey conducted by Department of Energy \& Climate Change, UK [16]. The data has a resolution of 10 minutes and contains the power consumption profile for each household devices. The data set also consist of different consumer profile categories and the corresponding consumptions. The extracted data is processed to obtain the instances of operation and the rating of device is considered as the maximum power consumed. The representative sets of profiles corresponding to Table I are illustrated in Figure 1. The same household on a working day and holiday display different consumption patterns as illustrated in Figure 2. The loads considered in the domestic environment in the present case and their corresponding inconvenience value are provided in Table IIError! Reference source not found. The value of $B_{i j}$ is 1 if it is a critical load and the value is less than 1 if non-critical. This study assumes values for each device $B_{i j}$ based on the programmers knowledge and intuition and can be altered by user anytime. These values are set to be the same for each household so set the base for the presented calculations. More devices are categorized as non-critical loads to increase the solution space.

The DR program is initiated when a reduction request is provided. However, in this study peak periods are assumed and corresponding to the peak period, a random reduction request is generated. The assumed peak periods are (7AM to 9:30AM), mid-day (12PM to 01:30PM) and evening (6PM to 9:30PM). These timings have been selected based on intuition and can be altered whenever required, but they represent peak demand periods in respect to a general demand profile under consideration. The simulation is performed for every 10 minutes w.r.t the resolution of data constituting 144 intervals

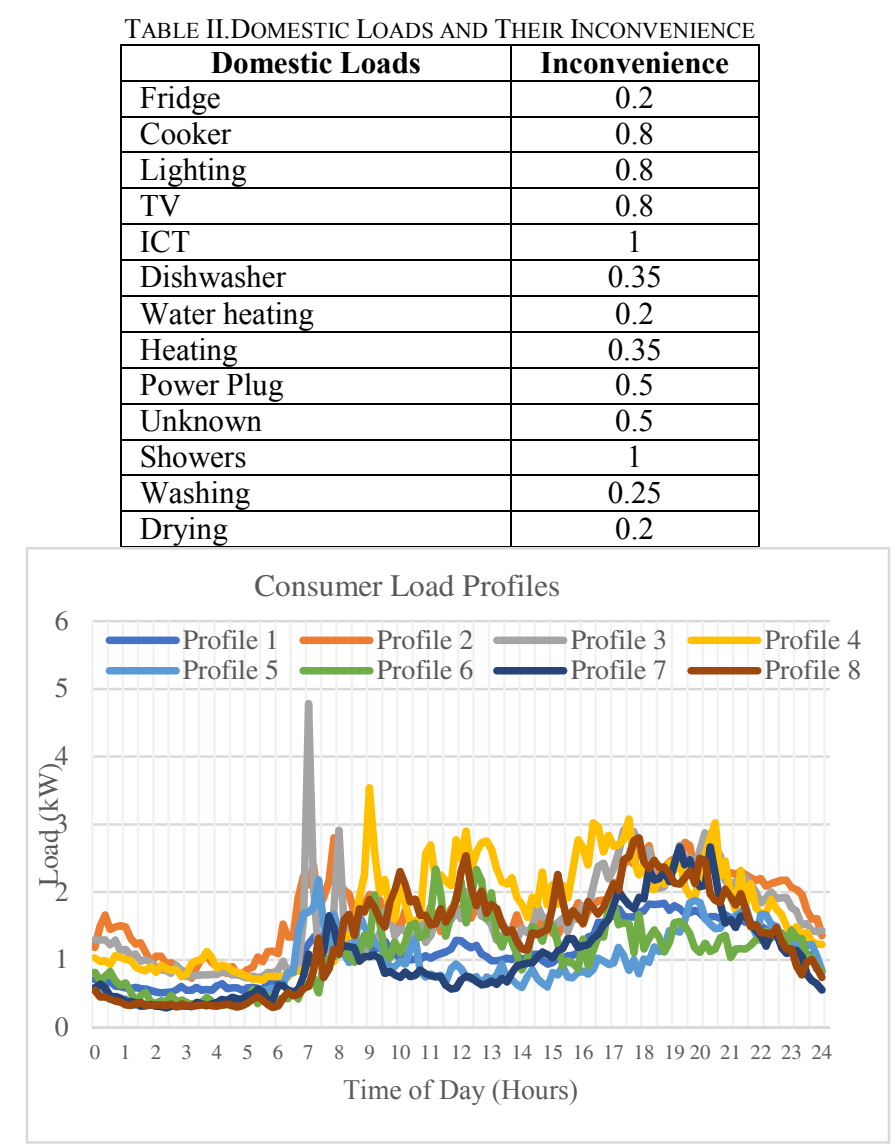

Figure 1. Load profiles of 8 categories of consumers

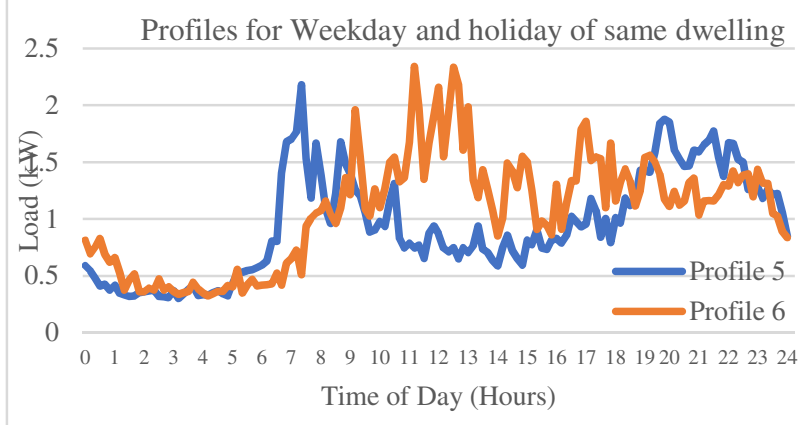

Figure 2. Load profiles for Weekday and Holiday for a Flat Dwelling

The first stage of DR is initiated with an initiation of the consumer engagement plan for consumers. The consumers with different profiles are distributed into the different engagement plans maintaining a reasonable ratio of consumers from each category with each engagement plan. The reduction request is received during the peak period and is distributed between the consumers based on their engagement plan. Evident in Table III, is that the amount of reduction contributed by each consumer is based on the engagement plan, thus providing consumer choices to participate according to their convenience rather than committing fully to load reduction. The algorithm generates individual house load reduction request which would be the input for the second stage. 
The second stage of the MILP-DR initiates a similar approach as the first stage but produces a device operating schedule based on the device operation demand. The schedule is generated based on the corresponding inconvenience factor of each device and the load reduction requested. The algorithm is smart enough to identify infeasibility if the reduction request demanded cannot be generated from the house, and thus would scale down the reduction request by $20 \%$ to solve again. This approach progresses as long as the algorithm finds a feasible solution. Further, the algorithm keeps count of operation and denial operation status which enables them to bring back the load during off peak time. Each device is given a minimum runtime as well, and hence cannot be switched off when started till the runtime is completed. Typically, a washing machine is given 10 intervals constituting a runtime of 1 hour 40 minutes. Devices like refrigerators, heaters, etc are not brought back the same amount of time they are denied operation as they are capable of maintaining a reasonable performance even when switched off for a short period of time. This enhances the efficiency of the system as well as helping the consumers to reduce their load.

The MILP-DR is performed on the 74 house urban distribution network based on the residential load demand data obtained. The 74 consumers representing 8 different consumer categories (based on Table I) are classed into four different consumer engagement plans. Their contribution on overall load reduction is presented as percentages in Table III. The table is colour coded for different engagement plans. The primary observations is, the load reduction contribution of each consumer is based on the engagement plan chosen. The Reluctant class of consumer isn't contributing any reduction as expected. The green aware category are least participating while the super green savvy are the largest participant Figure 3, represents the load profile and corresponding DR for a consumer with super green savvy engagement plan. The variation of their tolerance while engaging in the DR shows the capability of algorithm to account for fairness in consumers participating which would regulate the contribution of a consumer through time. This along with efficient communication would be an attractive feature of the program compelling consumers to utilize the benefits of DR.

Considering the objective to analyze the impact of social profiling on performance of DR, observations from Table IV show that, with higher number of residents results in a minor impact on DR as the shiftable loads generally are not allocated based on the number of occupants. With increasing numbers of people (occupants), an increase in the overall load in the house is evident and in this regard, this is indicative of critical loads that are associated to people. The shiftable loads such as, the washing machine, dishwasher, heating etc. remains the same. If analyzed for a longer period (week), could provide additional usage of non-critical load that may be shiftable. However, in a day to day DR, this may not be very useful right away. Further, children appear to increase the number of loads as well as shiftable loads. The assumption for such an inference is in respect to increasing cleaning and maintenance requirements being associated with children present in the house, which give a clear implication of dependency of performance of DR with respect to social status. Another interesting observation from
Figure 2 and Table IV is that, even though the load for same social profiles is relatively higher for holiday periods compared to the workday, the DR load reduction achieved is higher on a workday compared to a holiday. The assumption for such an observation is that the load is spread along the day more and during the peak times. In such instances, the house has a lower load demand (peaks period) in holiday periods compared to work days. Thus, proposed DR algorithm is able to respond to load profiles and does not force a reduction always. This further enhances the acceptability of the DR program.

\begin{tabular}{|c|c|c|c|c|c|c|c|c|c|}
\hline & Profile 1 & Profile 2 & Profile 3 & Profile 4 & Profile 5 & Profile 6 & Profile 7 & Profile 8 & \\
\hline & $11.02 \%$ & $13.56 \%$ & $11.48 \%$ & $8.92 \%$ & $12.50 \%$ & $11.84 \%$ & $14.06 \%$ & $15.83 \%$ & SGS \\
\hline & $\square 5.80 \%$ & $7.37 \%$ & $6.95 \%$ & $7.07 \%$ & $8.41 \%$ & $75.66 \%$ & $9.90 \%$ & $10.49 \%$ & GV \\
\hline & $3.49 \%$ & $3.64 \%$ & $2.84 \%$ & $3.09 \%$ & $\square 3.68 \%$ & $2.38 \%$ & $\square 4.21 \%$ & $\square 3.93 \%$ & GA \\
\hline & $0.00 \%$ & $0.00 \%$ & $0.00 \%$ & $0.00 \%$ & $0.00 \%$ & $0.00 \%$ & $0.00 \%$ & $0.00 \%$ & $R$ \\
\hline & $13.54 \%$ & $15.44 \%$ & $9.97 \%$ & $10.63 \%$ & $14.29 \%$ & $10.12 \%$ & $12.10 \%$ & $13.88 \%$ & SGS \\
\hline & $3.29 \%$ & $8.73 \%$ & $4.71 \%$ & $5.41 \%$ & $7.03 \%$ & $\$ .68 \%$ & $11.73 \%$ & $9.49 \%$ & GV \\
\hline & $4.52 \%$ & $2.90 \%$ & $2.72 \%$ & $2.68 \%$ & $2.90 \%$ & $2.70 \%$ & $\square 4.80 \%$ & $3.91 \%$ & GA \\
\hline & $0.00 \%$ & $0.00 \%$ & $0.00 \%$ & $0.00 \%$ & $0.00 \%$ & $0.00 \%$ & $0.00 \%$ & $0.00 \%$ & $\mathbf{R}$ \\
\hline & $11.89 \%$ & 15.129 & $10.08 \%$ & $10.43 \%$ & $15.45 \%$ & $9.41 \%$ & $13.11 \%$ & $15.22 \%$ & SGS \\
\hline & $6.22 \%$ & \begin{tabular}{|l|l|}
$83 \%$ \\
\end{tabular} & & & & & & & GV \\
\hline
\end{tabular}

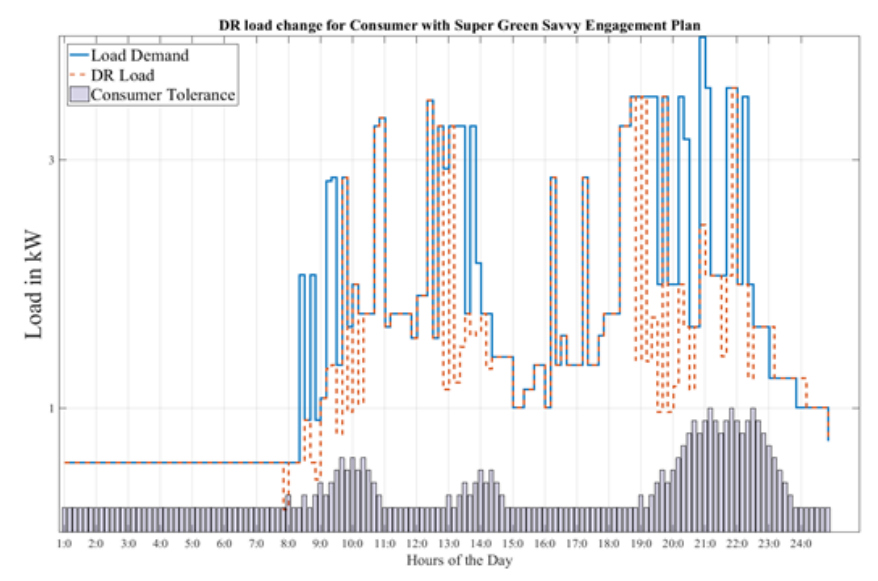

Figure 3. DR load change for Consumer with Super Green Savvy Engagement Plan

TABLE IV .LOAD REDUCTION IN KILO WATT FOR CONSUMERS OF DiFFERENT CATEGORY BASED ON ENGAGEMENT PLANS

\begin{tabular}{|l|c|c|c|c|c|c|c|c|c|}
\hline $\begin{array}{l}\text { Consu } \\
\text { mer No }\end{array}$ & Profile 1 & Profile 2 & Profile 3 & Profile 4 & Profile 5 & Profile 6 & Profile 7 & Profile 8 & \\
\hline $1-8$ & 3.82 & 5.16 & 3.46 & 2.76 & 4.58 & 4.55 & 4.29 & 6.03 & SGS \\
\hline $9-16$ & 2.01 & 2.62 & 2.12 & 2.01 & 2.89 & 2.05 & 2.96 & 3.96 & GV \\
\hline $17-24$ & 1.22 & 1.28 & 0.82 & 0.88 & 1.25 & 0.86 & 1.39 & 1.51 & GA \\
\hline $15-32$ & 0.00 & 0.00 & 0.00 & 0.00 & 0.00 & 0.00 & 0.00 & 0.00 & R \\
\hline $33-40$ & 4.96 & 5.41 & 2.90 & 3.03 & 4.88 & 3.66 & 3.57 & 5.24 & SGS \\
\hline $41-48$ & 2.12 & 3.06 & 1.37 & 1.63 & 2.57 & 2.42 & 3.86 & 3.62 & GV \\
\hline $48-56$ & 1.72 & 1.05 & 0.79 & 0.76 & 0.99 & 0.98 & 1.42 & 1.48 & GA \\
\hline $57-64$ & 0.00 & 0.00 & 0.00 & 0.00 & 0.00 & 0.00 & 0.00 & 0.00 & R \\
\hline $65-72$ & 4.01 & 5.29 & 2.92 & 2.97 & 5.27 & 3.41 & 3.87 & 5.75 & SGS \\
\hline $73-74$ & 2.10 & 2.92 & 0.00 & 0.00 & 0.00 & 0.00 & 0.00 & 0.00 & GV \\
\hline
\end{tabular}




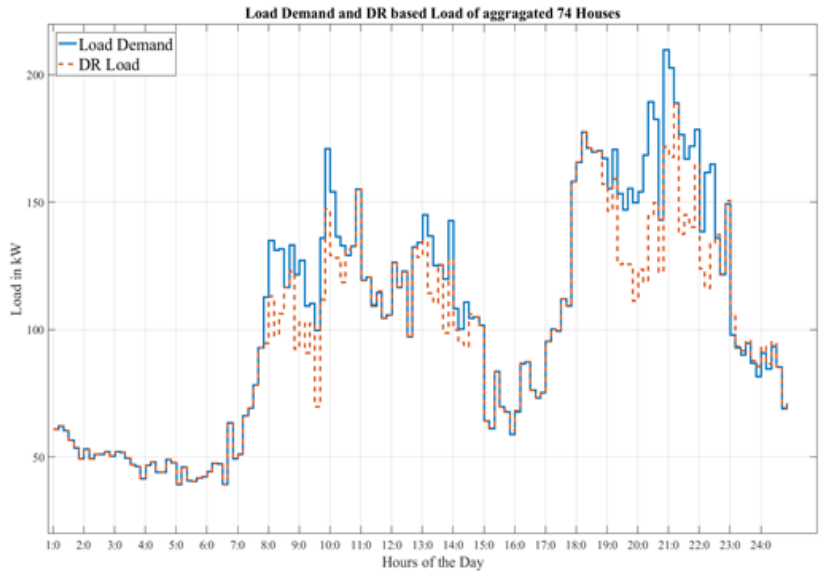

Figure 4: Total Load and DR load of 74 consumers

Figure 4, shows the aggregated load demand and the associated load reduction. The total overall reduction in load achieved for the day is $6.6 \%$. However, instantaneous reduction has peak impact of ca36\% at certain times, with peak rebound of $12 \%$. The amount of reduction possible, as discussed earlier, can depend on various factors. A careful modelling, along with efficient consumer profiling, can enable an aggregator to micromanage the demand in the network while improving the economics related and improving the efficiency of electrical devices.

\section{CONCLUSION}

The MILP-DR model presented in this work and its associated performance investigation (attempting to enhance the acceptability of DR to consumers), has highlighted its capability in considering the consumer load, inconvenience and social parameters. The DR was effectively able to distribute the load reduction based on the engagement plans allocated to each consumer. The DR was also able to establish fairness between the consumers chosen to load reduction without penalising them for being available. The capability of the algorithm to shift the load to an off-peak period, was also observed along with its contribution to improving the efficiency. The social profile based data was used to account for consumer demand. The observations suggest that the DR is not very sensitive to the number of people in the house, rather it has higher co-relation to the size and type of house. Further, it also shows that the presence of children in the house increases the size of shiftable load enabling the DR to achieve higher reduction. The DR has higher operability when the load profile has higher concentration during the peak time rather than a more spreadout load profile. The proposed algorithm with a fast and efficient communication system, consumer notification system and better profiling will have a higher conviction to consumers to participate in the energy management program like DR.

\section{REFERENCES}

T. Boßmann and E. J. Eser, "Model-based assessment of demand-response measures - A comprehensive literature review," Renew. Sustain. Energy Rev., vol. 57, pp. 1637 1656, 2016.

[2] A. R. Jordehi, "Optimisation of demand response in electric power systems, a review," Renew. Sustain. Energy Rev., vol. 103, no. September 2017, pp. 308-319, 2019.

[3] S. H. Madaeni and R. Sioshansi, "Using demand response to improve the emission benefits of wind," IEEE Trans. Power Syst., vol. 28, no. 2, pp. 1385-1394, 2013.

[4] S. Shao, M. Pipattanasomporn, and S. Rahman, "Grid integration of electric vehicles and demand response with customer choice," IEEE Trans. Smart Grid, vol. 3, no. 1, pp. 543-550, 2012.

[5] C. Chen, J. Wang, Y. Heo, and S. Kishore, "MPC-based appliance scheduling for residential building energy management controller," IEEE Trans. Smart Grid, vol. 4, no. 3, pp. 1401-1410, 2013.

[6] S. Li, D. Zhang, A. B. Roget, and Z. O’Neill, "Integrating home energy simulation and dynamic electricity price for demand response study," IEEE Trans. Smart Grid, vol. 5, no. 2, pp. 779-788, 2014.

[7] K. Dehghanpour, M. Hashem Nehrir, J. W. Sheppard, and N. C. Kelly, "Agent-Based Modeling of Retail Electrical Energy Markets with Demand Response," IEEE Trans. Smart Grid, vol. 9, no. 4, pp. 3465-3475, 2018.

[8] A. Nikoobakht, J. Aghaei, M. Shafie-Khah, and J. P. S. Catalão, "Assessing Increased Flexibility of Energy Storage and Demand Response to Accommodate a High Penetration of Renewable Energy Sources," IEEE Trans. Sustain. Energy, vol. 10, no. 2, pp. 659-669, 2019.

[9] Y. Guo et al., "Machine learning-based thermal response time ahead energy demand prediction for building heating systems," Appl. Energy, vol. 221, no. March, pp. 16-27, 2018.

[10] N. U. Hassan et al., "Framework for minimum user participation rate determination to achieve specific demand response management objectives in residential smart grids," Int. J. Electr. Power Energy Syst., vol. 74, pp. 91-103, 2016.

[11] N. Ul Hassan, Y. I. Khalid, C. Yuen, and W. Tushar, "Customer engagement plans for peak load reduction in residential smart grids," IEEE Trans. Smart Grid, vol. 6, no. 6, pp. 3029-3041, 2015.

[12] P. T. Baboli, M. Eghbal, M. P. Moghaddam, and H. Aalami, "Customer behavior based demand response model," IEEE Power Energy Soc. Gen. Meet., pp. 1-7, 2012.

[13] "Power companies dangle free nights and weekends - CBS News." [Online]. Available: https://www.cbsnews.com/news/power-companies-danglefree-nights-and-weekends/. [Accessed: 18-May-2019].

[14] "European Commission - PRESS RELEASES - Press release - Commission welcomes political agreement on conclusion of the Clean Energy for All Europeans package." [Online]. Available: http://europa.eu/rapid/press-release_IP18-6870_en.htm. [Accessed: 18-May-2019].

[15] "Survey Shows Utility-Customer Relationship Hinges on a Few Key Moments - MarketWatch." [Online]. Available: https://www.marketwatch.com/press-release/survey-showsutility-customer-relationship-hinges-on-a-few-keymoments-2015-04-01. [Accessed: 18-May-2019].

[16] "Energy Consumption in the UK - GOV.UK." [Online]. Available:

https://www.gov.uk/government/collections/energyconsumption-in-the-uk. [Accessed: 28-May-2019]. 